\title{
ANALYSIS OF THE EFFECTIVENESS OF USING POWER IN LEADERSHIP
}

\section{Endang Solichin}

Economic Education Department, STKIP YPM Bangko, Indonesia

\section{ARTICLE INFORMATION \\ Received : 01/09/2019 \\ Revised : 11/09/2019 \\ Issued: $21 / 09 / 2019$ \\ E-mail: $\underline{\text { Solend27@yahoo.co.id }}$}

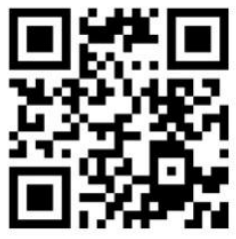

DOI:10.31933/DIJMS
Abstract: Institutions that can survive and thrive are institutions that have leaders who have a vision of very sharp changes and are able to transform organizational capabilities to build competitiveness. The success of a leader is largely determined by the ability to know and use the right kind of power in accordance with the demands of the situation. The purpose of this study is to analyze the effectiveness of the use of different kinds of power in leadership. These types of powers are expertise, reference power, reward power, legal authority and coercive power. This research was conducted at STKIP YPM in Merangin district, Jambi Province, Indonesia. The sample in this study were 30 lecturers from a population of 66 lecturers. Analysis of the data used to answer the objectives of this study is the Spearman Rank-Order Correlation with a significant level of $5 \%$. This research results that the use of expertise power, reference power, legal power and coercive power does not have a significant correlation with the attitude of commitment of the lecturers while the use of reward power has a significant negative correlation with the attitude of commitment of the lecturer.

Keywords: Leadership, Vision, Power.

\section{INTRODUCTION}

Leaders have a very dominant role in creating change in an organization, a leader's vision will determine how and in what direction the change will be directed. In the Industrial Age 4.0 typical leadership is more needed because management alone is not enough to answer the evolving challenges.

A leader must have a sharp vision in making changes or must have big leaps forward. Being a leader is not just about making changes or even being trapped into routine and bureaucratic activities, but must have a vision of the future that is able to divide the sea of problems so that people can cross over safely and prosperously.

Vision is a central component of great leadership, vision is a picture of the future desired by the leader about the organization they lead (Timothy, 1996). It is leadership that gives birth to a vision and strategy that is a logical idea of how the vision will be achieved while management 
gives birth to plans (plans, specific steps and schedules for implementing) and budgets (plans that are translated into projections and financial goals) (Kotter, 1996).

The search for the right leader with vision and strategy in making the leaps forward becomes a very important issue and is always sought in various organizations including educational institutions. Educational institutions as agents of change are the foremost element because educational institutions are the kitchen of creativity and innovation which are the core of a change in the era of the industrial revolution 4.0. The problem is how to find such a leader figure, even after the discovery of an ideal leader, he will be faced with various demands, especially the environment, community culture and available resources. Often the idea of changing a leader must fail and be stranded when he is dealing with the environment and culture of the community or organizational culture that exists, so that in practice a leader must be able to get out of the crush with his creative ideas. Community culture or organizational culture that has been patterned and existing regulations often become a prison wall for the creativity of a leader. On the other hand a leader must be able to transform organizational capabilities to build institutional competitiveness, therefore the success of a leader in achieving his goals is more determined by dynamic and effective leadership. This is based on an assumption that almost all organizational failures are caused by ineffective leadership (Drucker, 1960). Dynamic leadership is a pattern of behavior of a leader in using the power or authority he has in accordance with the needs and demands of the situation, meaning that he is not rigid in using his power, but he can change quickly in accordance with the demands of the situation.

\section{LITERATURE REVIEW}

The leader is the main resource that is very important in an organization or institution, because its policies will give color to the organization or institution. The leader shows the position while the leadership shows the process or activity influencing people to try to achieve group goals voluntarily (Terry, 1960). Thus the essence of leadership is to influence the attitudes and behavior of others. Success in influencing others is made possible by the availability of various kinds of power possessed by the leader.

Power is a very important thing because the essence of leadership is the problem of influence and the essence of influence is power. The success of a leader is largely determined by his ability to understand the situation and skills in determining the right type of power to respond to the demands of the situation and at the same time skills in using that power. Power is the potential of an agent to influence the attitudes and behaviors of others (target person) (Yukl, 1994).

Power refers to the capacity A has to influence B, so that B does something that inevitably has to be done. The most important aspect of power is that power is a function of dependency. The general dependency proposition suggests that the greater the dependence of $\mathrm{B}$ on $\mathrm{A}$, the greater the power A has on B. If A has whatever is needed by others but only A himself is in control, A makes them dependent on A and hence A gains power over they (Robbins, 1996). Dependence increases when the controlled resource is perceived as important, scarce and cannot be replaced.

There are two main types of power namely personal power which in its use has a negative tendency, the other side of power is identified as social power which in its use has a positive tendency, with its characteristics namely attention to group goals, assisting groups in formulating their goals, taking initiation in achieving group goals, making group members achieve goals and 
making group members strong and capable (Luthan, 1995). Effective leadership can bring positive change that helps organizations to improve and be innovative in today's business environment. How leadership influences other factors such as trust, culture and clear vision in the organization when facilitating change (Hao dan Yazdanifard, 2015).

The main difference between the definitions of leadership effectiveness is the form of effect or outcome chosen as an effective criterion. Which includes criteria for outcomes such as group performance, group results, group survival, group growth, group preparedness, group capacity in dealing with crises, subordinate satisfaction with leaders, subordinate commitment to group goals, good mentality and developing of members group. The habits commonly used to measure the effectiveness of leaders are:

1) How much the group leader or organizational performance is successful in the task and achieving the goals. Objective measures of performance or achievement of goals such as increased profits, profit margins, increased sales, market share, sales that reach relative targets, investment returns, productivity, perunit costs, costs associated with budget expenditures and so on. On the other hand subjectively the effectiveness of leaders is obtained from superiors, friends and subordinates.

2) Attitudes of followers towards leaders are other indicators of leader effectiveness, how leaders give satisfaction to their needs and expectations, followers 'actions such as respect, admiration for leaders, high commitment to achieve or meet leaders' demands or will they resist, ignore or subvert.

3) Attitude of followers is usually measured by questioner or interview. Variations in measurement objects of behavior such as absenteeism, rotation, complaints to top management, requests to move, setbacks, deliberate sabotage of equipment and facilities are indirect indicators of subordinate dissatisfaction and hostility towards leaders.

4) The effectiveness of the leader is measured by the leader's contribution to the quality of the group process, member cooperation, member motivation, problem solving, decision making and resolving conflicts between members. Is the leader's contribution to efficiency, organizational activities, accumulation of resources and group readiness in facing change and crisis. Do leaders make changes in work life, build self-esteem from followers, add to their skills and contribute to their psychological development (As'as, 1982).

\section{RESEARCH METHODS}

The purpose of this study is to analyze the effectiveness of the use of different kinds of power in leadership. These types of powers are expertise, reference power, reward power, legal authority and coercive power. This research was conducted at STKIP YPM in Merangin district, Jambi Province, Indonesia. The sample in this study were 30 people from a population of 66 lecturers. Analysis of the data used to answer the objectives of this study is the Spearman Rank Order Correlation with a significant level of $5 \%$.

\section{Empirical data and analysis}

The results of the data analysis showed that the use of expertise, reference power, legal authority and coercive power did not have a significant relationship with the commitment attitude of the lecturers, while the use of reward power had a significant negative relationship with the commitment attitude of the lecturers. 


\section{FINDINGS AND DISCUSSION}

The use of expertise power with the attitude of subordinates has no significant relationship. This is because the lecturers' tasks are structured based on their expertise, besides that the lecturers also have a high level of specialization so that they have maturity in their respective fields of work.

They do not see the expertise of their superiors as a force that encourages them to do something because in their field they can be more masterful. The results of this study prove that the structured tasks they have to do are supported by the skills and expertise they have, so that for specific matters lecturers directly dealing with operational tasks will know more about the situation in the field so that the specific knowledge they have is a source of counter power for lecturers.

The power of expertise will be effective in an organization whose task structure and maturity level is still low where the skills and expertise are concentrated in the superiors while subordinates do not have the skills. Conversely, if the skills and expertise are distributed at the lower level, the skills and expertise of the superiors do not so much affect the attitudes and commitments of subordinates.

The power of reference is based on a person's attractiveness, a leader is admired by his followers because it has a characteristic, this form of power is called charisma. Charisma occurs when there is a social crisis in a crisis of a leader with extraordinary personal abilities appearing with a radical vision that provides a solution to the crisis.

Charismatic power is needed when subordinates really need socio-emotional support to reach a level of maturity, where subordinates no longer need socio-emotional support. Organizations whose subordinates are still immature The emergence of charismatic leaders is a need to be able to provide support to members.

The results of this study indicate that the lecturers have socio-emotional capabilities and skills and expertise in their fields so that they no longer need social support from their superiors.

The use of reward power with the attitude of the lecturer shows a negative correlation meaning that an increase in reward in the form of salary will decrease the attitude of the lecturer towards the supervisor, so an increase in reward will not give satisfaction to the lecturer but only reduces dissatisfaction so that it does not increase their attitude or commitment towards their supervisor.

The results of this study reinforce the Herzbberg model of job satisfaction theory which states that job satisfaction and job dissatisfaction are two different things, it divides the situation that affects the work into satisfier and satisfier groups, namely the factors or situations that prove as a source of job satisfaction while the dissatisfied group the factors that prove to be a source of dissatisfaction, included in this group is salary. Salary improvement will not cause job satisfaction but only reduce job satisfaction.

The use of legal power with lecturer commitment shows no significant relationship. Legal power is often the most common reason given for compliance and often does not correlate with commitment. Compliance is a result in which the target is willing to do what is asked but he is apathetic and unenthusiastic and will do the least while the commitment he agrees with the agent's demands and he will make a big effort, carry out a statement or carry out decisions efficiently.

Research shows that there is no significant relationship between the use of coercion power with the attitude of lecturers. The results of this study strengthen Yukl and Falber's research 
which proves that coerciver power is not consistent between these sources of power and the criteria are usually negative or not. This use of coercive power should be avoided unless it is absolutely necessary because it is difficult to use and is likely to produce undesirable side effects such as hate and can even backfire, especially when applied to people who have a high level of maturity. The use of coercive power is unlikely to result in commitment and if used skillfully only results in obedience rather than resistance.

The results of this study indicate that only the use of reward power has a significant negative relationship with the attitude of subordinates, so to increase and maintain power with the use of reward power, it must be found what is needed and desired by lecturers, get more control in rewards, make sure the lecturers know that the leader controls the rewards, don't promise more than can be given, don't use the rewards in a manipulative way.

\section{CONCLUSION}

The use of expertise power is not effective in institutions where skills and expertise are already distributed to lecturers, given the existence of structured tasks and a high level of expertise. The use of reference power will be effective in an institution that is still newly established, unstable or an institution that is experiencing a crisis with a low level of specialization and task structure.

While the use of legal and coercive power does not have a significant relationship with the attitude of the lecturers towards superiors. The use of coercive power is difficult to produce the most committees only produce compliance or do not fight, therefore it is best to use coercive power unless avoided. The use of reward power shows a significant negative relationship as a dissatisfied group increasing salary will only reduce dissatisfaction.

\section{REFERENCE}

As'as, Moch, 1982 , Kepemimpinan Effektif Dalam Perusahaan, Edisi ke V, penertbit Liberty Yogyakarta.

Drucker, PF, 1960, Management : Task Responsibilities Practices, Harper \& Row, New York.

Galpin, Timothy J, 1996, The Human Side of Change, USA jassey Boss Inc.

Kotter Jp, 1996, Leading Change, Harvard Business Press, New York.

Luthan, Fred, 1995, Organizational behavior, Seventh Edition, MC Graw -Hill, Inc.

Moo Jun Hao \& Dr. Rashad Yazdanifard, 2015, How Effective Leadership can Facilitate Change in Organizations through Improvement and Innovation. Volume 15 Issue 9 Version 1.0 Publisher: Global Journals Inc. (USA) Online ISSN: 2249-4588 \& Print ISSN: 0975-5853.

Robbins, Stephen P, 1996, Organizational Behavior, Edisio Bahasa Indonesia, Perilaku Organisasi (Konsep -Kontroversi-Aplikasi)

Terry, GR, 1960, Principle of Management , 3 Rd edt. Record D Irwin, Inc Illions. Yukl GA, 1994, Leadership in Organizations , Practice Hall International 